\title{
O FLAMING (OU VIOLÊNCIA VERBAL EM MÍDIA DIGITAL) E SUAS FUNÇÕES NA ESFERA PÚBLICA
}

\author{
Anna Elizabeth Balocco* \\ Universidade do Estado do Rio de Janeiro \\ Centro de Educação e Humanidades \\ Departamento de Letras Anglo-Germânicas \\ Rio de Janeiro, RJ, Brasil
}

\begin{abstract}
Resumo: Este artigo discute a função do flaming (KAYANY, 1998) na esfera pública, a partir de um estudo de caso de comentários eletrônicos publicados em um site de notícias, após campanha eleitoral da Presidente Dilma Roussef, em 2015. Para tanto, são introduzidos os conceitos de esfera pública (HABERMAS, 1991) e discurso polêmico (AMOSSY, 2011). Para a análise do corpus, são adotadas categorias analíticas de Bousfield (2008) para o estudo da impolidez na linguagem. Foram identificadas, no corpus, ameaças à face positiva e negativa dos interlocutores. Argumenta-se que a violência verbal aparece de forma sistemática, endereçada a um interlocutor imaginário que se coloca, no espectro ideológico, em campo oposto ao do locutor. Embora não contribua para uma esfera pública em moldes habermasianos, caracterizada pelo debate racional de questões de interesse coletivo, o flaming pode ser visto como uma rotina interacional usada para delimitar diferentes posições discursivas no âmbito do discurso polêmico.
\end{abstract}

Palavras-chave: Flaming. Linguagem ofensiva. Impolidez. Mídia digital. Comentário eletrônico.

\section{INTRODUÇÃO}

A linguagem hostil e agressiva tem sido estudada de diferentes perspectivas, no âmbito dos estudos da linguagem. Culpeper (2011) toma o arcabouço teórico de Brown e Levinson (1987) sobre o fenômeno da polidez como ponto de partida para a análise de aspectos linguísticos da 'linguagem usada para ofender'. Para o autor, há pelo menos duas condições necessárias para a ocorrência de ofensa verbal: a linguagem deve estar em conflito com as expectativas (baseadas em normas sociais) do interlocutor, em relação à forma como ela lhe é endereçada; a linguagem deve produzir, pelo menos junto ao interlocutor direto, o efeito perlocucionário de ofensa (ou ter consequências emocionais negativas). Há vários outros fatores que podem exacerbar a ofensa verbal, mas estes não seriam condições necessárias para a mesma.

Argumenta ainda Culpeper (2011) que estas percepções são relativas ao contexto: aquilo que é considerado ofensivo, para determinado interlocutor, em certa situação, pode não ser percebido da mesma forma em situação distinta. No âmbito da mídia digital,

\footnotetext{
* Doutora em Linguística pela Universidade Federal do Rio de Janeiro. Pós-doutora em Estudos da Linguagem pela Universidade Federal Fluminense. Prof. Associada da UERJ (Pós-graduação em Letras). E-mail: annabalocco@terra.com.br.
} 
Amaral (2012) elaborou uma dissertação de mestrado que examina o funcionamento discursivo do dispositivo Twitter, em contexto situacional de grande envolvimento emocional (jogos da Copa do Mundo) e relata resultados em que a ocorrência de linguagem de baixo calão e agressiva é motivada, não somente pela interação em tempo real, mas também pela polarização dos participantes do evento discursivo, que se posicionam em campos antagônicos.

O fenômeno do flaming (ou violência verbal em mídia digital) parece ser o resultado direto do funcionamento discursivo da mídia digital, que permite a aparição de um "eu" anônimo, passional, regido apenas por seus impulsos e não pela razão (BALOCCO, 2016). Além de uma tendência à des-individualização ou despersonalização da mídia digital, outro argumento frequentemente citado na literatura é o de que a interação via mídia digital não incorpora os traços não verbais e contextuais da interação face a face, tais como as expressões faciais, a gesticulação, o tom de voz, dentre outros fatores da situação imediata em que se dá a interação. Esta redução de recursos expressivos levaria à busca de elementos para compensar aquela falta, na expressão verbal da emoção, indiretamente motivando um impacto reduzido das normas sociais que regulam as interações verbais.

Estes argumentos têm sido questionados, a partir de diferentes tradições teóricas. Amossy (2011), por exemplo, argumenta que a linguagem agressiva e polarizada, embora possa ser relacionada a alguns traços da mídia digital, não resulta exclusivamente desta. Para a autora, a linguagem hostil e agressiva de internautas não deve ser vista como comportamento verbal que foge às regras de convívio social, mas como uma intervenção discursiva no âmbito de debates públicos, motivada por características do discurso polêmico.

O estudo de Balocco e Shepherd (no prelo) contribui para esta última tradição de pesquisas, ao adotar um enfoque descritivo ao flaming, sem qualquer pretensão de um juízo de valor sobre o fenômeno. Para tanto, as autoras comparam os traços de um corpus de textos coletados em um site de notícias, após campanha eleitoral da Presidente Dilma Roussef em 2015, àqueles de um corpus de referência, levando em consideração certas variáveis do seu contexto de produção. A proposta das autoras, assim, não é a caracterização da linguagem agressiva ou hostil, mas investigar a relação entre mídia digital e violência verbal.

Os comentários (ou posts) eletrônicos são publicados em diferentes sites da internet; há comentários em blogs, em sites de notícias, em redes sociais, como o Facebook, ou o Twitter, dentre várias outras possibilidades. O presente trabalho centra-se unicamente na análise de comentários em sites de notícias, com o objetivo de levantar questões relevantes para os estudos do discurso e das práticas sociais.

Para reunir elementos para esta reflexão, serão articulados os conceitos de discurso político (VAN DIJK, 1997), esfera pública (HABERMAS, 1991), esfera pública midiatizada e flaming (KAYANY, 1998), além dos conceitos de discurso polêmico (AMOSSY, 2011) e gênero do discurso (o comentário eletrônico e sua funcionalidade).

Com base nestes elementos e na análise empírica de comentários eletrônicos postados no site de notícias oglobo.com, a partir de categorias para o estudo da impolidez na linguagem de Bousfield (2008), pretende-se discutir a seguinte questão: quais são as 
funções do flaming na esfera pública midiatizada? E qual a contribuição (se alguma) dos comentários com violência verbal para os debates públicos?

Nas seções a seguir, busca-se conceituar o fenômeno do flaming; introduz-se a metodologia da pesquisa, para, em seguida, proceder-se à discussão dos conceitos de esfera pública e esfera pública midiatizada, que darão consistência à tentativa de caracterização das funções do flaming no corpus de pesquisa.

\section{COMO CONCEITUAR E DEFINIR O FENÔMENO DO FLAMING?}

O'Sullivan e Flanagin (2003) indicam que o termo flaming tem origem no discurso leigo de comunidades virtuais, com o sentido de um comportamento verbal negativo, com o poder metafórico de incendiar um debate, ou "fritar" um internauta.

$\mathrm{O}$ fenômeno do flaming, ou linguagem usada intencionalmente para ofender, tem sido estudado em diversas abordagens, desde a área dos estudos da comunicação e da psicologia social, até a área dos estudos da linguagem. Na maior parte destes estudos, o flaming é visto como um fenômeno característico das mídias digitais (THOMPSEN; FOULGER, 1996), que favoreceria a aparição de um sujeito anônimo e passional, movido apenas por suas paixões e não pela razão. Já Lea et al. (1992), Sullivan e Flanagin (2003) e Amossy (2011) problematizam a vinculação do flaming à esfera digital, argumentando que o fenômeno é motivado por fatores exteriores àquelas mídias digitais.

Há vários problemas analíticos na conceituação do flaming, pois este é um fenômeno complexo, que depende de normas culturais, locais e interacionais, que variam no tempo e têm formas distintas em função de seus suportes interacionais. A interpretação de um enunciado contendo linguagem ofensiva depende, em última análise, da compreensão que tem, um indivíduo em particular, das normas operando em dada troca interacional.

Apesar destas dificuldades, Kayany (1998, p. 1137-1138) define uma ocorrência de flaming, ou um flame, como "uma expressão de hostilidade, livre de inibições, tal como xingar, injuriar, ridicularizar, lançar insultos a outra pessoa, seu caráter, religião, raça, inteligência, e habilidades física ou mental”. Em relação a esta definição, Amossy (2011) levanta a indagação se qualquer uso de linguagem ofensiva, ou contendo injúrias, pode ser incluída no âmbito do flaming.

Para a autora, é preciso distinguir entre o uso gratuito de linguagem ofensiva e o uso de linguagem ofensiva no interior de um quadro de conflito. No primeiro caso, observa-se a transgressão de normas de conduta verbal (facilmente caracterizado como comportamento livre de inibições e uma violência verbal sem propósito e sem direção). No segundo caso, no entanto, a violência verbal acomoda-se, não a uma situação particular de interação problemática (O’SULLIVAN; FLANAGIN, 2003), mas a um quadro mais amplo de negociação de sentidos tensa, que se desenvolve a partir de um contexto de "trocas agonísticas" (AMOSSY, 2011), ou situadas num ambiente de dissenso.

Neste estudo de caso, adota-se a mesma perspectiva discursiva de Amossy, de abordar o flaming no âmbito do discurso polêmico, caracterizado pela polarização (ou 
pela existência de um contra-discurso antagonista) e pela tentativa de desconstrução do outro. A ocorrência de flames, neste contexto, parece ser a norma, antes do que a exceção: os flames são previsíveis (eles obedecem a regras tácitas); não levam à interrupção da interação; constituem, antes, uma rotina interacional, cujas funções serão discutidas neste estudo.

\section{METODOLOGIA}

A coleta de textos para o corpus de estudo aconteceu durante o período póseleitoral: a primeira coleta de comentários foi feita em 10/08/2015, após notícia sobre a participação do senador Aécio Neves em evento público, em que convoca os brasileiros a aderirem à manifestação contra a presidente Dilma Roussef. A segunda coleta ocorreu em 11/08/2015, após notícia sobre o presidente Lula e a Marcha das Margaridas, convocada para dar apoio à presidente.

Embora não se trate de campanha eleitoral, os candidatos e os internautas que postam comentários comportam-se como se estivessem em campanha, expressando suas posições a favor ou contra o impeachment da presidente Dilma. Pode-se, assim, afirmar que se trata de uma situação, se não de conquista de poder, pelo menos de garantia de poder conquistado nas urnas, de um lado, e de ameaças ao poder, de outro. Isto, por si só, motiva a ocorrência de linguagem radical e polarizada no corpus.

Como o site é de domínio público, decidiu-se por identificar os comentários publicados. Alguns internautas usam apelidos em suas postagens, outros usam seus nomes completos, ou apenas os seus nomes de batismo. Os fragmentos retirados do corpus são identificados, também, por sua ocorrência após a primeira notícia (SC1, subcorpus 1) ou após a segunda notícia (SC2, subcorpus 2). Os comentários são apresentados sem revisão, da forma como publicados, com erros de gramática, de pontuação, de ortografia, dentre vários outros.

\section{Tabela 1 - Perfil do corpus}

\begin{tabular}{|l|l|l|l|l|}
\hline Corpus estudo & Participantes & Comentários & No. de Palavras & Publicação \\
\hline Subcorpus 11 & 19 & 67 & 1.422 & $11 / 08 / 2015$ \\
\hline Subcorpus 22 & 31 & 29 & 2.962 & $10 / 08 / 2015$ \\
\hline Total Corpus & 50 & 96 & 4.384 & - \\
\hline
\end{tabular}

\footnotetext{
Disponível em: <http://oglobo.globo.com/brasil/lula-dilma-apostam-em-movimentos-sociais-paracontrapor-acoes-de-oposicionistas-17145765>. Acesso em: 11 ago. 2015.

2 Disponível em: <http://oglobo.globo.com/brasil/aecio-diz-que-nao-cabe-ao-psdb-escolher-melhordesfecho-para-crise-17143221>. Acesso em: 11 ago. 2015.
} 
A relação entre o número de participantes e o de comentários atesta a densidade das trocas interacionais no site de notícias. Os participantes postam seus comentários, mas também respondem a outros internautas, ou os atacam.

No que diz respeito ao tratamento dos dados, foram adotados os seguintes procedimentos. Na identificação da linguagem agressiva e hostil, observaram-se os seguintes critérios. Em primeiro lugar, foi etiquetado o léxico marcadamente valorativo, em expressão cuja função é injuriar, ou ofender a honra (por exemplo, "vai sair ladrão e entrar outro ladrão"; "bando de oportunistas"; "Srs. Petistas, integrantes da Organização Criminosa vulgo PT"; "Clepto Collor").

Foi igualmente etiquetado o léxico marcadamente valorativo, em expressão cuja função é o insulto pessoal, como nos exemplos: "são muito otários esses petistas"; "bando de desocupado com bolsa"; "os baderneiros"; "Aécio Neves e Eduardo Cunha, Os achacadores do Brasil"; "UNE, esses vaggabundos marginais".

Os xingamentos também foram etiquetados, como nos seguintes exemplos: "VAGA BONDS"; "fodam-se a Dilma, o Lula e principalmente os eleitores e simpatizantes da Organização Criminosa vulgo PT"; "a corjjja de filhos da puta"; "um zé buc.. desses"; "d[esses] comentaristas chupadores de rôla".

E, finalmente, foram etiquetadas expressões que desqualificam o outro. Por exemplo, em "[Glauber] brigou com seu garotão", o internauta é alvo de ofensa, de teor marcadamente homofóbico. Em "[Glauber], fique de quatro pastando enquanto um jumento ti cobre por trás", a ofensa é exacerbada, pois, além de uma ofensa pessoal, constitui uma ofensa à honra do internauta.

A partir destes procedimentos de identificação, foram aplicadas as categorias de Bousfield (2008) para o estudo da impolidez na interação, exemplificadas no decorrer da análise. As categorias analíticas de Bousfield localizam-se no quadro mais amplo do modelo linguístico usado para os estudos da polidez de Brown e Levinson (1987). Tais categorias permitem caracterização mais eficiente de usos de impolidez, se contrastadas com o uso exclusivo de categorias lexicais, na análise do fenômeno.

Tendo delineado a metodologia e os princípios teóricos que norteiam o trabalho, introduzem-se, nas seções a seguir, os conceitos de discurso político e de esfera pública, de forma a entender se o fenômeno da linguagem hostil pode ser acomodado no âmbito de uma discussão da natureza da esfera pública e de suas funções políticas.

\section{OS POSTS EM SITES DE NOTÍCIAS PODEM SER CONSIDERADOS INSTANCIAÇÕES DO DISCURSO POLÍTICO?}

O primeiro compromisso do analista do discurso é indagar se há algo no funcionamento discursivo das mídias digitais que permite a ocorrência da linguagem do ódio. No caso do comentário eletrônico, há três traços principais de sua funcionalidade que poderiam ser vistos como favorecendo a linguagem do ódio: 1) o mesmo não é editado pelo site, e não sofre cortes, sendo antes publicado em sua integralidade, não havendo censura de termos ofensivos; 2) o comentário é produzido em tempo real, o que abre a possibilidade de interação entre internautas que comentam a mesma notícia postada 
no site; em geral, a interação entre os internautas resume-se à troca de ofensas verbais; 3 ) o post é feito por um internauta anônimo, que não assume responsabilidade criminal por seus comentários, frequentemente de teor homofóbico, racista, ou misógino. Seriam estas as condições exclusivas que motivam a linguagem da ofensa pessoal, tornando desnecessário o trabalho de face entre interlocutores?

Nossa hipótese de trabalho aproxima-se da de Amossy (2011), que postula que o flaming não deve ser atribuído exclusivamente a aspectos do funcionamento discursivo do suporte digital. Assim, uma pergunta que se impõe, imediatamente, diz respeito à natureza da ordem do discurso ${ }^{3}$ com a qual se está lidando: os comentários eletrônicos poderiam ser tratados como instanciações do discurso político, que faria emergir uma subjetividade da paixão, do sentimento irrefletido, e não da razão ou da reflexão?

Para examinar tal hipótese, apresentamos considerações sobre o discurso político e discutimos sua aplicabilidade ao corpus de comentários eletrônicos coligidos para este estudo. Para Laclau e Mouffe (1985, p. 153), o discurso político pode ser entendido de duas formas. Em sentido estrito, é aquele que apresenta demandas situadas ao nível dos partidos políticos e do Estado. Em sentido mais abrangente, no entanto, ele pode ser entendido como o discurso que cria, reproduz, ou transforma relações sociais.

Observa-se que, no seu sentido estrito, a definição de discurso político para Laclau e Mouffe (1985) baseia-se em critério vinculado ao enunciador do discurso. O discurso político aqui estaria representado pelos pronunciamentos, acordos, peças legislativas, executivas, ou de outra natureza, emitidos por figuras públicas como deputados, senadores, presidentes, procuradores da República, dentre outras possibilidades. Já para Pinto (2012), os espaços clássicos de enunciação do discurso político foram ampliados pelas mídias impressa, audiovisual, ou digital, que colocam em circulação a voz de jornalistas, cidadãos, ou especialistas, que, especialmente em períodos de campanhas eleitorais, tornam-se enunciadores de discurso político.

O discurso político pode e deve ser entendido, segundo Pinto (2012), de forma ampla, como toda e qualquer tentativa de fixar sentidos em relação a certo processo político, sempre de forma precária e passível de contestação, em um cenário de disputa. Essa disputa se dá no contexto de um quadro conflitual, que repercute, direta ou indiretamente, sobre aquele processo político (uma campanha eleitoral, uma tentativa de legislar sobre determinado assunto, um protesto em relação a determinado status quo, dentre outras possibilidades). O comentário de leitores em sites de notícias, assim, seria um exemplo destes novos espaços de enunciação do discurso político, visto que, nos posts, os internautas posicionam-se a respeito de certos processos políticos. No caso deste trabalho, expressam suas opiniões a favor ou contra o impeachment da Presidente Dilma Rousseff.

O problema com estas duas formulações é que, nelas, a conceituação de discurso político é muito abrangente, não levando em consideração, por exemplo, os diferentes

\footnotetext{
${ }^{3}$ Entende-se por 'ordem do discurso', segundo Fairclough (2003, p. 220), uma determinada configuração de gêneros, discursos e estilos, que constituem a dimensão discursiva de uma rede de práticas sociais. Assim, a ordem do discurso político comporta gêneros específicos (comícios, pronunciamentos, etc.), discursos característicos (conservador, liberal, etc.) e determinados estilos (formas de dizer e de argumentar próprias).
} 
efeitos de sentido que têm os discursos produzidos em locais de enunciação distintos. Os enunciados colocados em circulação em rodas informais de discussão, ou mesmo em comentários eletrônicos, na mídia impressa, ou televisiva, não se comparam, em termos de seus efeitos de sentido (de credibilidade, autoridade, legitimidade), àqueles codificados em pronunciamentos de figuras públicas da República.

Seria possível argumentar, ainda, que os locais de enunciação do discurso político também afetam a qualidade da interação entre os participantes discursivos. Por exemplo, em rodas informais de discussão, as opiniões tendem a ser atenuadas, tendo em vista a relação de proximidade entre os participantes daquele evento discursivo. Por outro lado, os comentários eletrônicos, como não são endereçados a interlocutores próximos, em termos de afeto ou relação social, não precisam necessariamente obedecer ao trabalho de face que incide sobre interações em que se observa menor distância social e/ou emocional (por exemplo, em comentários postados em redes sociais).

Para evitar os problemas analíticos que decorrem de uma conceituação muito abrangente do discurso político, acatamos argumento de Van Dijk (1997), segundo o qual a categorização de determinado discurso como político depende de sua funcionalidade, ou de o mesmo ter influência, direta ou indireta, sobre determinado processo político.

Os comentários eletrônicos não são diretamente funcionais nos processos políticos, no sentido de que não são enunciados produzidos em fóruns políticos, com repercussões sobre aqueles processos. Sendo assim, eles não devem ser entendidos como instanciações do discurso político, mas como parte constitutiva do discurso midiático.

No entanto, eles representam intervenções na esfera pública (via discurso midiático), dando visibilidade às posições antagônicas de atores sociais em determinado processo político. Trazemos para a próxima seção o conceito de esfera pública de Habermas, com o objetivo de encaminhar a discussão das funções do flaming.

\section{CONCEITO DE ESFERA PÚBLICA}

Habermas argumenta, em A transformação estrutural da esfera pública (1991), que tanto a natureza quanto as funções da esfera pública mudaram ao longo do tempo. Correndo o risco de reduzir o argumento do autor, apresentam-se alguns de seus eixos, buscando elementos para a compreensão da formação da esfera pública moderna, para em seguida contrapô-la à esfera pública midiatizada da modernidade tardia ${ }^{4}$.

A esfera pública, nas sociedades inglesa, francesa e alemã, formou-se, no século XVIII, como um espaço de natureza burguesa, em salões literários. O que contribuiu para a formação da esfera pública burguesa? A partir do século XVI, com a formação dos estados-nação e o início de um capitalismo mercantilista, observa-se a perda do poder feudal e a emergência de um novo estrato social, os burgueses (comerciantes, empresários, banqueiros), um conjunto de indivíduos que atua nas cidades, locais de trocas de mercadorias e de informações. Se no mundo feudal a esfera pública resumia-se

\footnotetext{
${ }^{4} \mathrm{O}$ termo 'modernidade tardia' é usado pelo sociólogo inglês Anthony Giddens, para referência aos dias de hoje, ao invés de 'pós-modernidade'. As razões para este uso são fornecidas pelo autor, em pelo menos dois livros $(1990 ; 1991)$.
} 
à teatralização do poder em palácios, na corte, ou em eventos cujo objetivo era dar visibilidade à "aura" ou prestígio do clero, da realeza ou da nobreza, no mundo pós-feudal a esfera pública (ou esfera da autoridade pública) passa a ser associada ao novo aparato do Estado moderno, com sua burocracia e seu sistema de tributação para atender às demandas crescentes de capital, necessário para a expansão do capitalismo mercantilista (HABERMAS, 1991, p. 17).

No século XVIII, forma-se uma esfera pública burguesa, que se localiza fora da esfera da autoridade pública (o Estado), em salões literários, a partir da discussão de produtos culturais acessíveis nos teatros, museus e concertos (HABERMAS, 1991, p. 29). Segundo Habermas, quando a cultura deixa de ser um elemento da Igreja ou da Corte, ela perde seu caráter "sacramental", é transformada em produto e pode ser "profanada", ou seja, tratada como algo que pode ser objeto de discussão (p. 37). A partir daí, as pessoas privadas passam a ter responsabilidade por determinar seu sentido e isto é feito na forma de uma discussão racional.

Do ponto de vista de sua função política, a esfera pública burguesa emerge como um espaço de defesa pública do caráter privado da sociedade. A discussão de objetos de cultura fornece o terreno para uma reflexão pública sobre questões privadas:

\begin{abstract}
A esfera pública burguesa pode ser entendida inicialmente como a esfera das pessoas privadas reunidas em um público; elas reivindicam esta esfera pública regulamentada pela autoridade, mas diretamente contra a própria autoridade, a fim de discutir com ela as leis gerais da troca na esfera fundamentalmente privada, mas publicamente relevante, as leis do intercâmbio de mercadorias e do trabalho social. (HABERMAS, 1991, p. 27) ${ }^{5}$.
\end{abstract}

Em um segundo momento, observa-se uma mudança estrutural da esfera pública burguesa. Este espaço, que se restringia aos cafés e salões literários, onde se formava o gosto e se expressavam juízos críticos, aos poucos amplia-se para abarcar a política e temas relevantes à vida coletiva. Daqui decorre a noção de que a crítica ao poder político nasce da crítica de arte: o princípio habermasiano de que qualquer cidadão, independente de títulos nobiliárquicos ou de qualquer outra natureza, tem o direito de expressar-se em relação à arte (a uma pintura, a um livro, ou a uma peça de teatro), bastando para tanto ter capacidade argumentativa, resultou numa concepção de crítica de arte como uma troca racional de argumentos (DA SILVA, 2001, p. 123). É este princípio iluminista ${ }^{6}$, da troca racional de argumentos na esfera pública, ampliado para a discussão de temas políticos, que vai fortalecer a função política da esfera pública burguesa, como fator de controle e de legitimação do poder exercido pelo Estado e seu aparato.

A esfera pública dos salões literários e, posteriormente, ampliada para o campo da política funda-se, argumenta Habermas, em certa subjetividade privada, voltada para si própria, característica da família patriarcal burguesa, e cresce no solo das ideias ligadas a um liberalismo econômico nascente, que se opõe ao absolutismo do rei: "as questões na

\footnotetext{
${ }^{5}$ Minha tradução do original em inglês.

${ }^{6} \mathrm{O}$ iluminismo ocidental do século XVIII caracteriza-se pelo apego às noções de razão, universalidade, transparência, além daquelas expressas nos ideais da Revolução Francesa: liberdade, igualdade, fraternidade.
} 
esfera da reprodução social [são ou devem ser tratadas como] uma questão de indivíduos privados, responsáveis por si próprios" (p. 74) ${ }^{7}$. A esfera pública burguesa seria então uma categoria da sociedade liberal, que afirma a primazia do indivíduo em relação ao Estado.

No final do século XVIII, emerge a chamada 'opinião pública', que se refere às reflexões críticas de um público competente para formar seus próprios argumentos: a imprensa na Grã-Bretanha foi vista, pela primeira vez, como um instrumento genuinamente crítico, de um público engajado em um debate público racional de ideias (p. 60). Já no final do século XIX, com o advento do capitalismo industrial, a emergência de uma democracia de massas e o aparecimento da indústria cultural, a esfera pública burguesa entra em decadência, observando-se uma mudança em sua natureza e uma "refuncionalização" de seus papeis. À medida que ela se estende ao domínio do consumo, argumenta Habermas (p. 160), a esfera pública enfraquece-se e torna-se apolítica. As instituições que até então garantiam a coerência do público, como uma entidade autônoma e capaz de conduzir o debate racional de ideias públicas, vão se enfraquecendo (p. 162).

De uma subjetividade privada, mas orientada para o debate público de ideias, passase a uma subjetividade desprivatizada pelas mídias de massa, que passam a adaptar-se ao gosto de seus consumidores. De um público que debate a cultura para um público que consome cultura, resume Habermas (p. 162).

Há várias leituras críticas do conceito habermasiano, centradas em dois núcleos principais: em primeiro lugar, critica-se a natureza do conceito como um construto idealizado, normativo, uma forma histórica específica da época em que é formulada (FRASER, 1990, p. 57). Tal construto só teria validade no interior do quadro do Iluminismo, em que a razão é vista como pensamento racional, crítico e transparente e no quadro do nascente liberalismo econômico, próprio da Europa do início do período moderno, que funciona como um contrapeso ao estado absolutista (1990, p. 59).

Outra vertente crítica aponta as limitações da constituição da esfera pública burguesa: a mesma não contempla vários setores da sociedade civil, como as mulheres, os operários, os trabalhadores "não-burgueses". Para Fraser (1990, p. 60), havia várias esferas públicas desde o início, não apenas a partir do final dos séculos XIX e XX, como argumenta Habermas.

\footnotetext{
Mais importante para o tema deste trabalho é a postulação de que o conceito de esfera pública habermasiano precisa ser repensado, pois se, por um lado, ampliou-se o seu alcance de forma inegável (com as mídias digitais), por outro, diminuiu-se consideravelmente o leque de suas funções políticas. Segundo Wolton (1995, p. 167), “[...] o espaço público contemporâneo pode ser designado por 'espaço público mediatizado', no sentido em que é funcional e normativamente indissociável do papel dos media."
}

Embora admita que a esfera pública deixou de ser constituída de forma homogênea, por uma camada culta, e passou a dividir-se em uma minoria de especialistas e uma massa de consumidores de informação, Habermas (1991) re-afirma a importância da esfera pública e a existência de um público crítico, participativo e racional, em contraponto à

\footnotetext{
7 “[...] a matter of private people left to themselves".
} 
massa amorfa de consumidores de informação, além de argumentar pelo papel relevante das mídias (ou meios de comunicação social) no levantamento de temas para debate público.

Chouliaraki e Fairclough (1999) caminham na mesma direção das críticas ao conceito habermasiano, ao observar que, enquanto as análises do espaço público moderno identificavam uma esfera pública unificada, análises recentes, na modernidade tardia, apresentam um cenário distinto: há muitas esferas públicas, organizadas em torno das agendas próprias de diferentes movimentos sociais (como o feminismo, a ecologia, dentre várias outras). No entanto, prosseguem os autores, interessa preservar, do conceito habermasiano, a ideia de que é da natureza da esfera pública o uso de uma forma particular de linguagem, aquela que se observa no debate racional de questões de interesse coletivo: "De forma a conseguirem agir de forma conjunta, as pessoas precisam dialogar" 8 .

Este diálogo não pressupõe o consenso, dizem Chouliaraki e Fairclough (1999); muito pelo contrário, ele comporta um espaço para a explicitação (inclusive polêmica) das diferenças e também para a construção de alianças, acima das diferenças ${ }^{9}$.

Trazendo novamente a discussão para o tema desta pesquisa, até que ponto os comentários eletrônicos se adequam à forma particular de linguagem usada para intervenção na esfera pública? Para aproximar-me desta questão, trago, na seção a seguir, considerações sobre a esfera pública midiatizada como forma de introduzir a polêmica sobre a existência ou não de uma esfera pública digital.

\section{A ESFERA DIGITAL: UM ESPAÇO PÚBLICO OU UMA ESFERA PÚBLICA?}

Butsch (2007) argumenta que as mídias digitais tornaram-se forças centrais na esfera pública no final do século vinte, dada a sua variedade, o seu alcance e a sua convergência. Para o autor, vivemos hoje uma era de intensos debates sobre o impacto das mídias nas instituições e na esfera pública, que poderia ser sintetizado na seguinte questão: quais mídias afetam que tipos de esfera pública?

As respostas a estas questões são contraditórias, mas todas as pesquisas que se ocupam da relação entre mídia e esfera pública tentam esclarecer em que medida as mídias contribuem para fortalecer ou prejudicar uma esfera pública democrática, com ampla participação dos vários grupos que constituem a sociedade. A esfera pública midiatizada tem o papel de levantar temas de interesse coletivo, como a esfera pública burguesa de Habermas? Tem a função de servir como controle e legitimação das instâncias de poder? E a função de manter-se como um espaço privado, fora do controle do estado?

\footnotetext{
${ }^{8}$ No original, em inglês: "In order to act together, people need to talk together." (CHOULIARAKI; FAIRCLOGH, 1999).

${ }^{9}$ Chouliaraki e Fairclough (1999, p. 64) não desconhecem os problemas colocados pelo conceito de 'diálogo', que depende da acessibilidade de todos à esfera pública; da simetria de papeis dos participantes; da liberdade de expor sua visão particular; do compromisso com a aliança, ou seja, com uma visão que ultrapasse a visão particular de cada participante.
} 
No que diz respeito às mídias digitais, Papacharissi (2002) argumenta que a internet pode ser vista como um “espaço público", mas não como uma "esfera pública” em moldes habermasianos, um espaço que promove uma troca racional e democrática de ideias e opiniões. A autora cita Lyotard (1984), por exemplo, que criticou o conceito habermasiano de esfera pública, argumentando que, mais do que o acordo racional, "o que leva à verdadeira emancipação democrática é a anarquia, a individualidade e o desacordo" (PAPACHARISSI, 2002). Fraser (1990), como vimos, ampliou as críticas a Habermas, observando que a esfera pública burguesa constituía um espaço para o exercício de liderança de homens privilegiados, que excluía mulheres e indivíduos nãoproprietários $^{10}$.

Embora não possa ser vista como uma esfera pública no sentido habermasiano, Papacharissi (2002) admite que a mídia digital "é uma ferramenta útil, que pode servir para dar um feedback direto para os políticos". E vai mais longe: a anonimidade das mídias digitais favoreceria a expressão mais franca e aberta de posições políticas ${ }^{11}$.

É com este entendimento e com a visão de que oflaming ocorre em um contexto de trocas interacionais situadas em um ambiente de dissenso (AMOSSY, 2011) que abordamos o corpus de estudo, nas seções a seguir.

\section{ESTRATÉGIAS DE IMPOLIDEZ (FLAMING) NOS COMENTÁRIOS ELETRÔNICOS}

Bousfield (2008, p. 1) argumenta que "os discursos contendo ilocuções polêmicas (algumas delas sendo constituídas de linguagem ofensiva) não são fenômenos marginais". Pelo contrário, em alguns discursos, a polêmica é mais central do que em outros, continua o autor, e cita Culpeper (2008), para alguns exemplos: o discurso do treinamento de oficiais no Exército, das cortes judiciais, da família, o discurso terapêutico, o discurso dos adolescentes, dentre vários outros.

A maior parte dos estudos voltados para a linguagem da impolidez toma como ponto de partida os estudos de Brown e Levinson, um modelo linguístico para o estudo do gerenciamento da face. Bousfield (2008) faz o mesmo, mas complementa seu quadro teórico analítico com o conceito de norma social (ou visão leiga da polidez), além do princípio das máximas conversacionais de Lakoff (1973) e de Leech (1983, 2005). No que diz respeito ao primeiro, o autor argumenta que é preciso olhar para a historicidade da polidez e para a forma como os leigos compreendem as normas sociais, algo que faltou no modelo de Brown e Levinson e foi consistentemente criticado.

Bousfield (2008, p. 72) define a impolidez como "o oposto da polidez". Se na polidez tenta-se mitigar atos que constituem ameaças potenciais à face, na impolidez tais atos são intencionalmente gratuitos e polêmicos. Os atos que ameaçam a face são, assim, produzidos: 1) de forma não mitigada, em contextos em que a mitigação é necessária,

\footnotetext{
${ }^{10}$ No original, em inglês, o termo é 'nonpropertied classes'.

${ }^{11}$ No original inglês: "relative anonymity encourages discussion participants to be more vocal and upfront about stating their beliefs."
} 
e/ou, 2) com agressão deliberada, ou seja, com a face exacerbada, de alguma forma maximizados para ampliar o dano infligido à face.

Além do mais, continua Bousfield (2008, p. 73), "para que haja impolidez, a intenção do locutor de ofender (ameaçar ou causar danos à face) precisa ser compreendida pelo interlocutor". Neste sentido, o autor acompanha Culpeper, que também argumenta que interessa, aos estudos da linguagem, não a impolidez acidental, mas aquela estratégica ou instrumental, que realiza uma função específica.

As categorias usadas por Bousfield (2008) são aquelas de Culpeper (2011), organizadas em torno das macroestratégias de ataque à face (positiva ou negativa) do interlocutor (p. 82). Por razões de espaço, apenas as estratégias realizadas no corpus de estudo serão descritas.

Predominam, no corpus, os ataques à face positiva do interlocutor, através de várias estratégias, que serão exemplificadas a seguir. A primeira delas é "Ofenda o seu interlocutor - use termos derrogatórios (injúrias, insultos)":

\section{Glauber • há 3 horas $(\mathrm{SC} 1)$}

Xamelez Aparecida, dizer que eu defendo o Lula é a prova de seu retardo mental. Faça o seguinte: fique de quatro pastando enquanto um jumento TI cobre por trás.

Aparecida Ferreira • há 3 horas $(\mathrm{SC} 1)$

Ê COM UM DETALHE.... ESSE GLAUBER COMEÇOU CEDO HOJE..... A MULHER DEVE TER COLOCADO ELE PRA FORA DA CAMA ...

Glauber • há 3 horas (SC1)

Múmia de extrema direita, viúva da dentadura, digo, ditadura. Todas as mehdas feitas pelo PT não apagam as mehdas feitas pela direitalha golpista.

Observa-se que as ofensas são de caráter sexual (muito comuns, no corpus), nos dois primeiros casos, e de natureza ideológica ("múmia de extrema direita"), no terceiro enunciado. Mas há também uma ofensa pessoal, no primeiro excerto ("prova de seu retardo mental").

Nestes exemplos, os internautas interagem em tempo real e ofendem-se, mutuamente, de forma direta. No entanto, podem ser considerados usos de impolidez enunciados em que os internautas não se dirigem a seus interlocutores, mas fazem comentários ofensivos sobre terceiros. Uma estratégia muito comum, nestes casos, é "Use linguagem tabu (use palavrões, seja abusivo, expresse opiniões fortes, opostas à de seu interlocutor)":

Imelton Pires de Azevedo • há 2 horas (SC1)

Olha só a cara de cachacei.. desse sujeito. Como pode um zé buc.. desses, ter tanta importância nesse país? Um país com 200 milhões de habitantes? Um povo que vota no Collor, no Renan, no Maluf ... Todo sofrimento para esses eleitores ainda é pouco.

Sergio Ricardo • há 2 horas ( $\mathrm{SC} 1)$

OLHEM A CARA DE D.E.S.E.S.P.E.R.O DESSE VERME. Hilário. 
Em exemplos como estes, não há troca direta entre os internautas. Os xingamentos, os palavrões, são atribuídos a terceiros (nos exemplos acima, ao ex-presidente Lula). Para quem estes enunciados são considerados ofensivos? As ofensas são dirigidas a qualquer outro internauta visitando o site, com posições diferentes daquelas de quem faz a postagem. É um Outro imaginário, de posição ideológica (contra ou a favor da presidente Dilma) distinta da do internauta.

Para Bousfield (2008, p. 138), para que os palavrões sejam considerados ofensivos, eles não precisam endereçar-se ao interlocutor, ou mesmo ser usados para dar ênfase a uma estratégia de impolidez dirigida ao interlocutor. $\mathrm{O}$ uso de palavrões, ou quaisquer outras formas de expressão consideradas tabu, pode ser ofensivo, nestes casos, pois é um uso de linguagem que causa desconforto àqueles que a ouvem. Há, no arcabouço teórico, uma estratégia ("Faça o seu interlocutor sentir-se desconfortável") que poderia representar estes usos de linguagem ofensiva.

No entanto, continua o autor, a questão da intenção de ofender deve ser problematizada. Neste estudo, depreende-se a natureza ofensiva da linguagem no cotexto: os internautas têm posições antagônicas, no interior de um quadro de dissenso, e ofendem seus interlocutores quando ofendem terceiros alinhados às suas posições. Isto fica claro em enunciados como o que segue:

\footnotetext{
Jorge Wehbeh • há 1 hora (SC2)

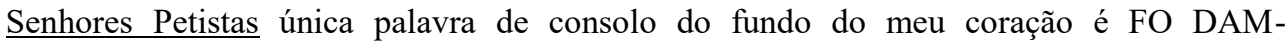
SEEEEEEEEEEEEEEEE a Dilma, o Lula e PRINCIPALMENTE os eleitores e simpatizantes do PT, Ex-tesoureiro do PT visitou sede da Andrade Gutierrez 53 vezes em sete anos, diz MPF, e ainda tem idio/ta que quer defender esses ladrões do PT.
}

Neste enunciado, a linguagem abusiva ("fodam-se") é atribuída a terceiros (à presidente Dilma, ao ex-presidente Lula, além de a "simpatizantes do PT"), mas o enunciado é claramente endereçado, através do uso do vocativo "Senhores Petistas", que dá consistência, no discurso, ao interlocutor imaginário do internauta. Ele ofende, não um interlocutor especificamente, mas todos aqueles ("senhores petistas") que figuram no contra-discurso antagonista.

Tanto no caso de ilocuções endereçadas a interlocutores específicos, quanto no caso de ilocuções não endereçadas (dirigidas a um Outro imaginário, localizado no contradiscurso antagonista), os enunciados ofensivos ameaçam a face positiva do interlocutor, ou seja, o seu desejo de reconhecimento, de ser visto de forma favorável. Mas foram observadas também ameaças à face negativa do interlocutor (seu desejo de preservar o seu território, sua liberdade de ação e permanecer livre de imposições).

Várias estratégias são usadas nos ataques à face negativa do interlocutor. A primeira delas é "Amedronte (seu interlocutor) - instile a crença de que ações prejudiciais a ele irão acontecer":

\footnotetext{
M Vogel • há 3 horas (SC2)

É nessa hora que eu gostaria que surgisse no Brasil um novo Hitler para colocar diante de um pelotão de fuzilamento toda essa turma do PT (Dies ist, wenn ich in Brasilien entstanden wünschen eine neue Hitler vor einem Erschießungskommando diese ganze Klasse von PT setzen)
} 
Neste enunciado, a internauta mobiliza os medos de seus antagonistas através da referência a Hitler e ao pelotão de fuzilamento. Como forma de exacerbar sua ameaça, a internauta repete-a em alemão, como se a adoção daquela língua tivesse o poder mágico de realizar a ameaça. Também aqui o enunciado é codificado em relação a um terceiro ("essa turma do PT") e não endereçada diretamente a um interlocutor, mas o fato de o coocorrer com enunciados de internautas em posição ideológica claramente contrária à da internauta é evidência de que há intenção de ofender.

Outra estratégia de ameaça à face negativa do interlocutor é "Condescenda, ou ridicularize seu interlocutor - enfatize o seu próprio poder, use diminutivos, demonstre desprezo, diminua o outro, não leve o outro a sério":

\begin{abstract}
Marcio Fabrini • há 3 horas (SC2)
Incrivel, ele foi no encontro dos senadores com a presidenta? Não. Mas na passeata vai. Né? Olha trabalhar que é bom ninguem quer. Mas fica de prosa contra o pais todo. Só um detalhe: O PT é uma droga, o Psdb idem, quem está ao lado ou atra da Dilma idem. O mais importante nisso que todos desastras delas e imperfeições adiministrativas. Ninguem pode meter o dedo na cara dela e dizer você é ladra. Agora isso eu não tenho certeza dos que querem o lugar dela e é muita gente. Acorda Brasil acorda.
\end{abstract}

A ofensa inicial ("vai na passeata mas não vai ao encontro dos senadores") é dirigida ao senador Aécio Neves, com o sentido de que ele não deve ser levado a sério. Este sentido é reforçado pela expressão "trabalhar que é bom ninguém quer", uma ofensa de caráter mais geral, haja vista o pronome indefinido ("ninguém quer trabalhar"), que se aplica tanto ao senador quanto a qualquer outro indivíduo que participe de passeata. Prova de que há também outro destinatário para o enunciado, todo aquele que não se alinha às posições do próprio internauta, fica evidente no último enunciado: "Acorda Brasil acorda." A convocação dirigida ao país é na verdade uma ameaça à face negativa dos leitores da notícia, através de uma outra estratégia, qual seja "Invada o espaço do outro literal ou metaforicamente".

No caso desta última ocorrência, a invasão de espaço é metafórica, entendendo-se que certas rotinas interacionais (ordens, perguntas de foro íntimo, proibições) são admitidas apenas quando a relação entre os participantes discursivos é próxima, o que não é o caso aqui. Em "Acorda Brasil acorda", o internauta dá ordens a um interlocutor indefinido, recuperado na metonímia 'Brasil', que tem como referente os brasileiros em geral. No exemplo a seguir, observa-se a mesma estratégia:

\footnotetext{
Francisco Franciam Dutra • há 4 horas (SC2)

Senador Aécio, desça do palanque, desde que terminou as eleições, você não faz outra coisa há não ser querer derrubar um governo eleito legitimante pelo povo brasileiro, se foi estelionato eleitoral, quem vai cobrar é o povo brasileiro nas próximas eleições, não queira ser o salvador da pátria, apenas não seja um irresponsável, apoiando manifestações contra um governo que está passado pela uma crise econômica e politica, TODA MANIFESTAÇÃO É JUSTA DESDE QUE SEJA PARA PROTESTAR E NÃO PRA DA GOLPE
} 
A ordem para o senador "descer do palanque" caracteriza-se como uma ameaça à sua face negativa, através da mesma estratégia de invadir o espaço do outro. Acresce a esta ameaça à face negativa do senador uma ameaça à sua face positiva, através da estratégia de "Xingue o outro - use termos derrogatórios": "não queira ser o salvador da pátria", "não seja um irresponsável".

Outra possibilidade de classificação aqui, em relação ao mesmo exemplo, seria entender que o enunciado realiza a estratégia "Force a mudança de papel [de seu interlocutor]" (BOUSFIELD, 2008, p. 131). Em "Senador Aécio, desça do palanque", a estratégia funciona ao convocar o senador a sair de um papel social (de candidato a presidente) e assumir outro (de senador da República). Trata-se de uma ameaça à face negativa do senador, pois invade o seu território, a sua liberdade de ação; ao mesmo tempo, funciona como uma ameaça à face positiva do senador, pois representa uma crítica à sua atuação "no palanque". A dupla ameaça (à face negativa e positiva) é frequente no corpus, como mostra o exemplo a seguir:

\footnotetext{
Arthur Fraga • há 16 horas (SC2)

O que cabe ao PSDB já "cabeu"! Como o Vasco da Gama, um "vice", nada mais, na última eleição. No mais, é o tradicional "jus esperniandi" de quem PERDEU A ELEIÇÃO POR MAIS DE 3 MILHÕES DE3 VOTOS. Pedir outra eleição é válido. Vai ter outra mesmo, mas no prazo constitucional. Golpe de mão, só na construção de aeroporto em terras de "parentes". Para Miami já, "pray-boy" capiau!
}

A ameaça à face negativa mais uma vez traduz-se em um enunciado com uma ordem ("para Miami, já"), que ameaça a liberdade de ação do senador. E o léxico valorativo (“"“pray-boy” capiau”) representa uma ameaça à face positiva do senador.

Mais uma vez é preciso lidar com a dificuldade analítica de um quadro que tem como condição necessária para a impolidez o reconhecimento, por parte do interlocutor, da natureza ofensiva do enunciado. O que justifica o reconhecimento destas ilocuções como ofensivas é que as mesmas buscam, intencionalmente, causar danos à face do outro. Ainda que este outro seja um terceiro, o dano à sua face (positiva ou negativa) é um dano à face daqueles que se alinham a ele, naquela faixa do espectro ideológico. Deveriam estes enunciados (que não ofendem diretamente seus interlocutores, mas terceiros) ser considerados "ameaças incidentais" à face (Bousfield, 2008, p. 68)?

Bousfield observa que as ofensas incidentais ocorrem quando há efeitos nãoplanejados de uma ação e dá como exemplo o questionamento, por parte de um indivíduo, de uma multa de trânsito. Quando resiste a aceitar a multa, o indivíduo ameaça a face do policial de trânsito, colocando em dúvida sua autoridade para penalizá-lo. É exatamente por esta percepção de que sua ilocução é uma ameaça potencial à face do policial que o indivíduo usa várias formas linguísticas para amenizar o impacto de seu enunciado.

No caso dos enunciados com ofensas a terceiros, aqui em discussão, as ameaças são intencionais, em primeiro lugar, tanto à face do terceiro quanto à daqueles que com ele se alinham, no espectro ideológico. Em segundo lugar, elas cumprem determinadas funções, quais sejam, 1) a de distanciamento no espectro ideológico; 2) a de dar nitidez às posições que animam os internautas. Damos sequência ao exame destas funções, na seção a seguir. 


\section{CONCLUSÃO: AS FUNÇÕES DO FLAMING NO ESPAÇO PÚBLICO DIGITAL}

A visão de Amossy (2011), de que o fenômeno do flaming deve ser visto no quadro mais amplo do discurso polêmico (que se desenvolve a partir de um contexto de trocas agonísticas), permite encaminhar uma discussão mais fundamentada sobre as funções do flaming no espaço público digital.

O primeiro ponto é anotar que a violência verbal no corpus não configura uso gratuito de linguagem ofensiva, no quadro de uma interação problemática com certo interlocutor (O'SULLIVAN; FLANAGIN, 2003), ou sequer artifício usado exclusivamente para expressar a indignação do internauta. Muito pelo contrário, o flaming no corpus de estudo aparece de forma sistemática, endereçado a um interlocutor imaginário, que se coloca, no espectro ideológico, em campo oposto ao do locutor, ou no âmbito de um contra-discurso. Neste sentido, o flaming pode ser visto como uma rotina interacional usada para delimitar diferentes posições discursivas, no âmbito do discurso polêmico.

Bousfield (2008) argumenta que a tentativa de classificar os usos de linguagem tabu e ofensiva, quer como expressão emocional (raiva, indignação, etc.), ou como ameaça estratégica à face do outro, de forma exclusiva (ou é isso ou é aquilo), não é produtiva: uma forma mais promissora de encaminhar uma análise deste tipo de linguagem seria em termos da distribuição dos seus usos, por tipo de participante discursivo. Quem pode usar linguagem abusiva e em que situações? De que forma esta distribuição é motivada por questões ligadas a poder, no discurso?

No caso dos internautas neste corpus de pesquisa, não há assimetria nas relações de poder entre os participantes discursivos, sendo assim as ofensas ocorrem dos dois lados. É preciso admitir que, em usos de linguagem ofensiva, ao invés de estar atento à face do interlocutor, o locutor tenta atacar e ameaçar a sua face, para cumprir certos propósitos extra-linguísticos (BOUSFIELD, 2008). O objetivo extra-linguístico dos internautas parece ser o de dar visibilidade às suas posições, explicitando suas diferenças na esfera pública.

Este seria um importante primeiro passo na direção de um discurso democrático, pois, sem o reconhecimento da diferença, não há possibilidade de se construir acordos. Nos termos de Chouliaraki e Fairclough (1999), o diálogo para construir acordos não pressupõe o consenso; muito pelo contrário, ele comporta um espaço para a explicitação (inclusive polêmica) das diferenças.

Retornando à questão de pesquisa que motivou este estudo, relativa à possibilidade de se acomodar o fenômeno do flaming no âmbito de uma discussão da natureza da esfera pública e de suas funções políticas, há dois pontos a serem considerados. Em primeiro lugar, no caso dos comentários eletrônicos em sites de notícias, é preciso interrogar-se sobre a conveniência de se tratar este espaço como uma esfera pública, no sentido habermasiano. Embora seja mais apropriadamente caracterizado como um "espaço digital", por sua fragmentação, esta mídia ainda se mantem como um espaço privado, fora do controle de instâncias de poder (seja jornalística, administrativa, estatal, ou qualquer outra). 
No entanto, o caráter privado desses espaços não parece ser suficiente para que se exerça, neles, a função de controle e legitimação das instâncias de poder, ou sequer a função de levantar temas de interesse coletivo, visto que os comentários configuram-se como reações a uma pauta da própria mídia. Não funcionam, neste sentido, como uma esfera pública, no sentido habermasiano.

Em segundo lugar, e para terminar fazendo uma afirmação sobre as características linguísticas do fenômeno estudado, o flaming, nos comentários eletrônicos analisados, materializa-se na forma de ameaças à face negativa ou positiva dos interlocutores, o que representa uma tentativa de desqualificar, ou reduzir ao silêncio, o Outro de um discurso antagonista. As ameaças à face são codificadas em linguagem radical e polarizada, que não cumpre os requisitos para a "forma particular de linguagem" própria do debate racional de questões de interesse coletivo. Assim vistos, os comentários eletrônicos não se qualificam para o estatuto de discurso democrático, aquele que pressupõe o compromisso com a aliança, ou com uma visão que ultrapasse a visão particular de cada participante discursivo (CHOULIARAKI; FAIRCLOUGH, 1999, p. 64) ${ }^{12}$. Somente o discurso democrático garantiria o funcionamento de uma esfera pública em moldes habermasianos.

Se não se qualifica para o estatuto de discurso democrático, e não se adequa às formas de dizer próprias do debate racional de questões de interesse coletivo, o discurso polarizado e radical das mídias digitais serve exclusivamente, como argumentam vários pesquisadores, ao propósito de criar um espetáculo para atrair leitores? ${ }^{13}$. Ou seria possível atribuir ao flaming outra função: a de teatralizar as posições discursivas, em um quadro de dissenso, dando corpo e forma às diferenças que animam aquele quadro?

No pequeno corpus de estudo, as intervenções dos internautas podem ser vistas como a expressão franca e aberta de suas posições políticas e a função do flaming parece ser a de conferir nitidez a essas posições discursivas, o que permite o gerenciamento de situações de conflito no espaço público, conforme argumento de Amossy (2011). Resta saber se a expressão franca e aberta de um conflito, garantida pela acessibilidade universal ao debate coletivo proporcionado pelas mídias digitais, pode compensar a perda de racionalidade do debate público.

Para Habermas, "o conflito e o consenso [...] não são categorias que permanecem refratárias ao desenvolvimento da sociedade" (1991, p. 250). A análise das transformações da esfera pública e de sua capacidade de assumir funções apropriadas "determina se o exercício da dominação e do poder persistem como uma constante negativa, por assim dizer, da história - ou se, sendo, elas mesmas [a dominação e o poder] categorias históricas, estão abertas a mudanças substantivas" (1991, p. 250). O presente estudo pretende contribuir para esta tradição de pesquisas, ao levantar questões sobre a função do flaming na esfera pública midiatizada.

\footnotetext{
${ }^{12}$ Cf. ainda Laclau (2005, p. 81): no discurso democrático, o social é feito de diferenças e as identidades sociais podem ser contraditórias, diferentemente do discurso populista, em que as relações entre identidades sociais são de puro antagonismo.

13 “[...] la mise en spectacle de la polémique à la fin de captation (Charaudeau, 2005)” (AMOSSY, 2011).
} 
AMARAL, M. S. A linguagem no Twitter: um enfoque sistêmico-funcional. 2012. Dissertação (Mestrado em Linguística) - Programa de Pós-graduação em Linguística, Universidade do Estado do Rio de Janeiro, Rio de Janeiro, 2012.

AMOSSY, R. La coexistence dans le dissensus. Semen [Online], v. 31, p. 25-42, 2011. Disponível em: $<$ http://semen.revues.org/9051 $\geq$. Acesso em: out. 2014.

BALOCCO, A. E. A representação de atores sociais em comentários eletrônicos: que figuras habitam o imaginário político dos brasileiros na atualidade? Gragoatá, Niterói, n. 40, p. 423-444, 1. sem. 2016.

; SHEPHERD, T.M.G. A violência verbal em comentários eletrônicos: um estudo discursivointeracional. Submetido à Revista D.E.L.T.A, PUC-SP, 2. sem. 2016.

BOUSFIELD, D. Impoliteness in interaction. Amsterdam / Philadelphia, John Benjamins. 2008.

BROWN, P.; LEVINSON, S. C. Politeness: some universals in language usage. Cambridge: Cambridge University Press, 1987.

BUTSCH, R. How are media public spheres? In: BUTSCH, R. (Ed.) Media and public spheres. London, Palgrave, McMillan, 2007.

Disponível em: <http://www.rider.edu/files/butsch_media_public_spheres.pdf >. Acesso em: 10 out. 2013.

CHOULIARAKI, L.; FAICLOUGH, N. Discourse in late modernity: rethinking critical discourse analysis. Edinburgh, Edinburgh University Press, 1999.

CULPEPER, J. Impoliteness: using language to cause offence. Cambridge and NY: Cambridge University Press, 2011.

DA SILVA, F.C. Habermas e a esfera pública: reconstruindo a história de uma ideia. Sociologia, problemas e práticas, n. 35, p. 117-138, 2001. Disponível em: $<$ http://www.ics.ul.pt/rdonwebdocs/n35a05.pdf $\geq$. Acesso em: nov. 2015.

FAIRCLOUGH, N. Analysing discourse: textual analysis for social research. London, Routledge, 2003.

FRASER, N. Rethinking the public sphere: a contribution to the critique of actually existing democracy.

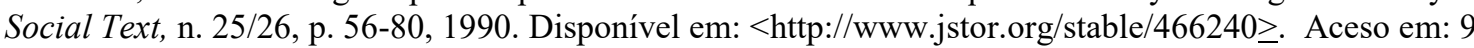
out. 2013.

GIDDENS, A. As consequências da modernidade. SP: Editora UNESP, 1991. [Ed. orig. 1990] Modernity and self-identity: self and society in the late modern age. California: Stanford University Press, 1991.

HABERMAS, J. The structural transformation of the public sphere: an inquiry into a category of bourgeois society. Massachusetts, The MIT Press, 1. Ed. em livro de bolso do MIT, 1991. [Ed. original alemã 1962, Hermann Luchterhand Verlag]

KAYANY, J. M. Contexts of uninhibited online behavior: Flaming in social newsgroups on Usenet. Journal of the American Society for Information Science. (Special Issue: Social Informatics). V. 49, n. 12, p. 1135-1141, 1998.

LACLAU, E.; MOUFFE, C. Hegemony and socialist strategy: towards a radical democratic politics. London: Verso, 1985.

On populist reason. London: Verso, 2005.

LAKOFF, R. The logic of politeness; or, minding your p's and q's. In: Papers from the Ninth Regional Meeting of the Chicago Linguistics Society, p. 292-305. Chicago Linguistics Society, 1973.

LEA, M.; O’SHEA, T.; FUNG, P.; SPEARS, R. 'Flaming' in computer-mediated communication: A recursive review. In: Lea, M. (Ed.), Contexts of Computer-Mediated Communication. (p. 89-112). New York: Harvester Wheatsheaf. 1992. Disponível em: $<\mathrm{http}$ ://martinlea.com/contributed-flaming-computermediated-communication-observations-explanations-implications/ $>$. Acesso em: nov. 2014.

LEECH, G. N. Principles of Pragmatics. London: Longman, 1983.

O'SULLIVAN, O. B.; FLANAGIN, A. J. Reconceptualizing 'flaming' and other problematic messages. New Media and Society, v. 5, n. 1, p. 69-94, 2003. Disponível em:

$<$ http://citeseerx.ist.psu.edu/viewdoc/download?doi=10.1.1.134.9223\&rep=rep1\&type=pdf $\geq$. Acesso em: jan. 2015. 
PAPACHARISSI, Z. The virtual sphere: the internet as a public sphere. New media \& society v. $4, \mathrm{n} .1$. London: Sage, 2002. p. 9-27. Disponível em: <http://nms.sagepub.com/cgi/content/abstract/4/1/9 . Acesso em: out. 2014.

PINTO, C. R. J. Elementos para uma análise de discurso político. Disponível em: $<$ http://online.unisc.br/seer/index.php/barbaroi/article/viewFile/821/605 $\geq$. Acesso em: 6 dez. 2012.

THOMPSEN, P.; FOULGER, D.A. Effects of pictographs and quoting on flaming in electronic mail. Computers in Human Behavior, 12, 225-243, 1996.

VAN DIJK, T. A. What is political discourse analysis? Belgian Journal of Linguistics, v. 11, n. 1, p. 11 $52,1997$.

WOLTON, D. As contradições do espaço público midiatizado. Revista de Comunicação \& Linguagens, Lisboa, n. 21-22, p. 167-188, 1995.

Recebido em: 02/06/16. Aprovado em: 27/0916.

Title: Flaming (or verbal violence in digital media) and its functions in the public sphere Author: Anna Elizabeth Balocco

Abstract: In this article, we are concerned with the function of flaming (hostile language) in the public sphere, drawing on a case study of electronic posts published in a news site, after President Dilma Roussef's electoral campaign in 2015. To this end, the concepts of public sphere (HABERMAS, 1991) and polemical discourse (AMOSSY, 2011) are introduced, as well as Kayany's (1998) conceptualization of flaming. For corpus analysis, Bousfield's (2008) categories for the study of impoliteness in language are adopted. It is argued that verbal violence (in the form of positive and negative face threats in the corpus) is systematic, addressed to an imaginary interlocutor positioned in an antagonistic field; and that, although flaming does not contribute to a Habermasian public sphere, characterized by the rational debate of public issues, it nonetheless serves the purpose of making distinct positions in discourse explicit, allowing for conflict situations to be managed in the digital sphere.

Key-words: Flaming. Hostile language. Impoliteness. Digital media. Electronic post.

Título: El flaming (o violencia verbal en media digital) y sus funciones en la esfera pública Autor: Anna Elizabeth Balocco

Resumen: Este artículo discute la función del flaming (KAYANY, 1998) en la esfera pública, desde un estudio de caso de comentarios electrónicos publicados en una portada de noticias, después de la campaña electoral de la Presidente Dilma Roussef, en 2015. Para ello son introducidos conceptos de esfera pública (HABERMAS, 1991) y discurso polémico (AMOSSY, 2011). Para el análisis de corpus son adoptadas categorías analíticas de Bousfield (2008) para el estudio da falta de cortesía en el lenguaje. Fueron identificadas en el corpus amenazas al lado positivo y negativo de los interlocutores. Se argumenta que la violencia verbal aparece de forma sistemática, direccionada a un interlocutor imaginario que se pone, en el espectro ideológico, en campo opuesto aquél de lo locutor. Aunque no contribuya para una esfera pública en modelos habermasianos, caracterizada por el debate racional de cuestiones de interés colectivo, el flaming puede ser visto como una rutina de interacción usada para delimitar diferentes posiciones discursivas en el ámbito del discurso polémico.

Palabras-clave: Flaming. Lenguaje ofensivo. Falta de cortesía. Media digital. Comentário electrónico.

Este texto está licenciado com uma Licença Creative Commons Atribuição 4.0 Internacional. 